\title{
DOAS measurements of $\mathrm{NO}_{2}$ from an ultralight aircraft during the Earth Challenge expedition
}

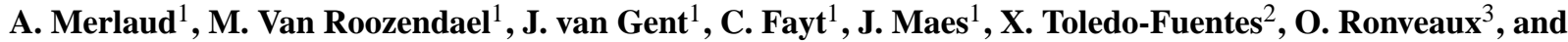 \\ M. De Mazière ${ }^{1}$ \\ ${ }^{1}$ Belgian Insitute for Space Aeronomy (BIRA-IASB), Avenue Circulaire 3, 1180 Brussels, Belgium \\ ${ }^{2}$ Research Centre in Physics of Matter and Radiation (PMR), University of Namur, Rue de Bruxelles 61, \\ 5000 Namur, Belgium \\ ${ }^{3}$ Usf-free sky, Rue du Page 65, 1050 Brussels, Belgium
}

Correspondence to: A. Merlaud (alexis.merlaud@aeronomie.be)

Received: 21 December 2011 - Published in Atmos. Meas. Tech. Discuss.: 28 February 2012

Revised: 30 June 2012 - Accepted: 23 July 2012 - Published: 24 August 2012

\begin{abstract}
We report on airborne Differential Optical Absorption Spectroscopy (DOAS) measurements of $\mathrm{NO}_{2}$ tropospheric columns above South Asia, the Arabic peninsula, North Africa, and Italy in November and December 2009. The DOAS instrument was installed on an ultralight aircraft involved in the Earth Challenge project, an expedition of seven pilots flying on four ultralight aircraft between Australia and Belgium. The instrument recorded spectra in limb geometry with a large field of view, a set-up which provides a high sensitivity to the boundary layer $\mathrm{NO}_{2}$ while minimizing the uncertainties related to the attitude variations. We compare our measurements with OMI (Ozone Monitoring Instrument) and GOME-2 (Global Ozone Monitoring Experiment 2) tropospheric $\mathrm{NO}_{2}$ products when the latter are available. Above Rajasthan and the Po Valley, two areas where the $\mathrm{NO}_{2}$ field is homogeneous, data sets agree very well. Our measurements in these areas are $0.1 \pm 0.1$ to $3 \pm 1 \times 10^{15}$ molec $\mathrm{cm}^{-2}$ and $2.6 \pm 0.8 \times 10^{16}$ molec $\mathrm{cm}^{-2}$, respectively. Flying downwind of Riyadh, our $\mathrm{NO}_{2}$ measurements show the structure of the megacity's exhaust plume with a higher spatial resolution than OMI. Moreover, our measurements are larger (up to $40 \%$ ) than those seen by satellites. We also derived tropospheric columns when no satellite data were available if it was possible to get information on the visibility from satellite measurements of aerosol optical thickness. This experiment also provides a confirmation for the recent finding of a soil signature above desert.
\end{abstract}

\section{Introduction}

Nitrogen dioxide $\left(\mathrm{NO}_{2}\right)$ is a key species both in atmospheric chemistry, through its role in the ozone cycle, and as an indicator of air quality. In the troposphere, its main sources are anthropogenic and related to fossil fuel combustion in car engines, thermal power stations and industries (Jacob, 1999). $\mathrm{NO}_{2}$ contributes to the photochemical smog seen above many cities and its effects on health have motivated the definition of acceptable exposure thresholds. The World Health Organization (WHO, 2003) recommends a maximum 1 -h exposure concentration of $200 \mathrm{\mu g} \mathrm{m}^{-3}$ and an annual average of $40 \mathrm{\mu g} \mathrm{m}^{-3}$. In this paper we present airborne Differential Optical Absorption Spectroscopy (DOAS) $\mathrm{NO}_{2}$ measurements during an ultralight aircraft expedition from Thailand to Belgium during November 2009.

The tropospheric $\mathrm{NO}_{2}$ loading can be remotely retrieved using its absorption bands in the ultraviolet-visible and the DOAS technique (Platt and Stutz, 2008). This is achieved from space by nadir-looking satellite-borne sensors like OMI (Ozone Monitoring Instrument) (Levelt et al., 2006) or GOME-2 (Global Ozone Monitoring Experiment 2) (Munro et al., 2006). These measurements are particularly valuable since they offer a global picture of the $\mathrm{NO}_{2}$ field. However, their spatial resolution is limited by the pixel size $\left(13 \times 24 \mathrm{~km}^{2}\right.$ for OMI, $80 \times 40 \mathrm{~km}^{2}$ for GOME-2), which does not resolve fine-scale patterns. Satellite data also suffer from instrument drifts and require validation involving mostly ground-based DOAS instruments (e.g. Kramer et al., 
2008; Herman et al., 2009; Pinardi et al., 2010; Shaiganfar et al., 2011), airborne in-situ measurements (Bucsela et al., 2008; Boersma et al., 2008) or, less frequently, airborne DOAS instruments (Heue et al., 2005). An aircraft is able to cover the spatial extent of a pixel in a short time, but such an experiment is expensive and requires dedicated aircraft.

Ultra-light aircraft are well suited for $\mathrm{NO}_{2}$ studies. Their ceiling is relatively low, but, at least in polluted zones, most of the $\mathrm{NO}_{2}$ is close to the surface. Aircraft modifications are much easier than on normal planes since they do not require certifications from the aeronautics authorities. Ultra-light aircraft have so far been used to study the actinic flux (Junkermann, 2001), the aerosol profiles (Chazette et al., 2007; Raut and Chazette, 2008) and formaldehyde distribution (Junkermann, 2009).

The Earth Challenge expedition (De Maegd, 2010), which took place in 2009, involved four ultralight aircraft flying from Australia to Belgium. It provided an opportunity to develop and test a new compact DOAS instrument, namely the Ultralight Motorized-DOAS (ULM-DOAS). In comparison with previous airborne DOAS experiments (e.g. Bruns et al., 2006; Prados-Roman et al., 2011; Merlaud et al., 2011), the optical set-up is very simple. We just record the scattered light intensity at the horizon within a large field of view without any telescope or scanner. However, this measurement geometry optimizes the sensitivity to boundary layer $\mathrm{NO}_{2}$ while it limits the errors due to aircraft attitude (pitch, roll, and yaw) instabilities.

In the next section we describe the technical aspects of the ULM-DOAS instrument and the Earth Challenge expedition. The methods used for the data analysis, i.e. the DOAS settings, radiative transfer modeling, and inversion schemes, are presented in Sect. 3. In Sect. 4, we study the sensitivity of our measurements to geometrical and geophysical parameters and propagate uncertainties on these parameters in an error budget. The methods and error analysis are applied in Sect. 5 to derive tropospheric $\mathrm{NO}_{2}$ above interesting areas for which few local measurements have been reported. We compare our measurements with OMI and GOME-2 data for the days where it is possible, and we investigate the presence of a soil signature recently reported in GOME-2 spectra.

\section{The ULM-DOAS instrument and the Earth Challenge expedition}

\subsection{Instrument description}

Figure 2 shows the ULM-DOAS, which was developed at the Belgian Institute for Space Aeronomy (BIRA-IASB) and first used during the Earth Challenge expedition. The light is collected by a $400 \mu$ m-diameter optical fiber, which, during operation, is attached under a wing of the aircraft, pointing forward to the horizon. There is no focusing element at the entrance of the fiber, hence the field of view is directly related

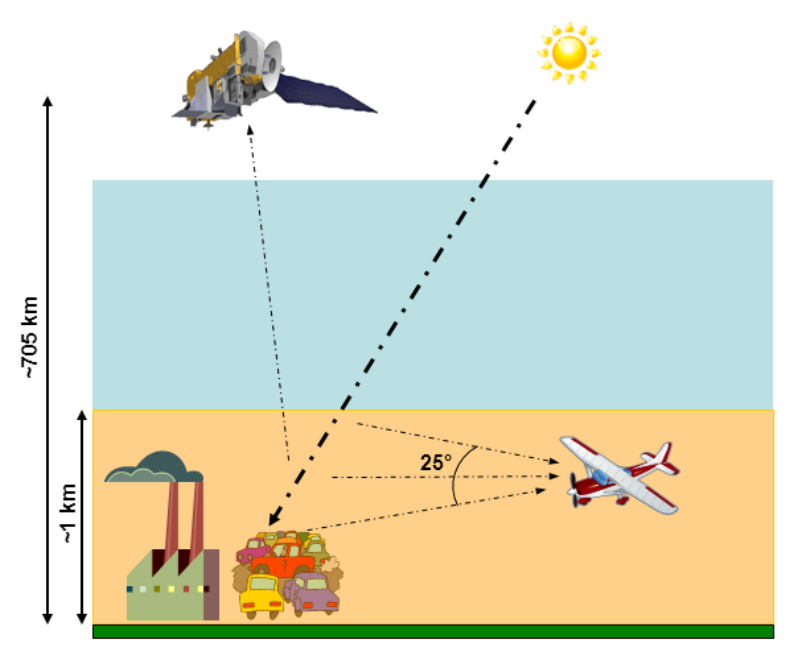

Fig. 1. Geometry of our ULM-DOAS measurements compared to a nadir-looking satellite instrument like OMI.

to the numerical aperture of the fiber, which corresponds to $25^{\circ}$ (Fig. 1). This choice is motivated in Sect. 4. A black plastic baffle (not shown) is added to limit the stray light. The other extremity of the fiber is screwed to the spectrometer, which lies inside a $27 \times 27 \mathrm{~cm}^{2}$ aluminum box together with a PC-104 that controls it. The spectrometer is an AvaSpec2048 with a $50 \mu \mathrm{m}$ entrance slit and a $6001 \mathrm{~mm}^{-1}$ grating, blazed at $300 \mathrm{~nm}$. It covers the spectral range from 200$750 \mathrm{~nm}$ at a resolution of approximately $1.2 \mathrm{~nm}$ Full Width at Half Maximum (FWHM) at $460 \mathrm{~nm}$. Figure 4 shows the slit function in the $\mathrm{NO}_{2}$ fitting window. The instrument sensitivity to polarization is under 4 per mil. The detector is not temperature-stabilized and the typical shift variation during a flight is $0.2 \mathrm{~nm}$. Both the spectral resolution and the shift are characterized in the DOAS analysis (Sect. 3.1). A GPS antenna is connected to the PC-104 for georeferencing the measurements. The whole set-up is powered by the aircraft's $12 \mathrm{~V}$.

While measuring, the instrument is recording spectra continuously at an integration time of $5 \mathrm{~ms}$. The noise is reduced by averaging a series of 10 accumulations on the CCD (charge-coupled device) to produce a spectrum. These spectra are transferred to the computer and filtered by the acquisition program, removing those with too low or saturated signal. A second averaging is then applied to a spectra series of $5 \mathrm{~s}$ to produce a final measurement point, the process being repeated continuously. The dark current is estimated from the mean of the signal in the range of $280-300 \mathrm{~nm}$, where the atmosphere is opaque due to ozone absorption. Preliminary DOAS analyses (see Sect. 3.1) with preconvoluted cross-sections are done in real time and saved on a USB key attached to the aluminum box. This allows for easy monitoring of the behavior of the instrument, especially when no 


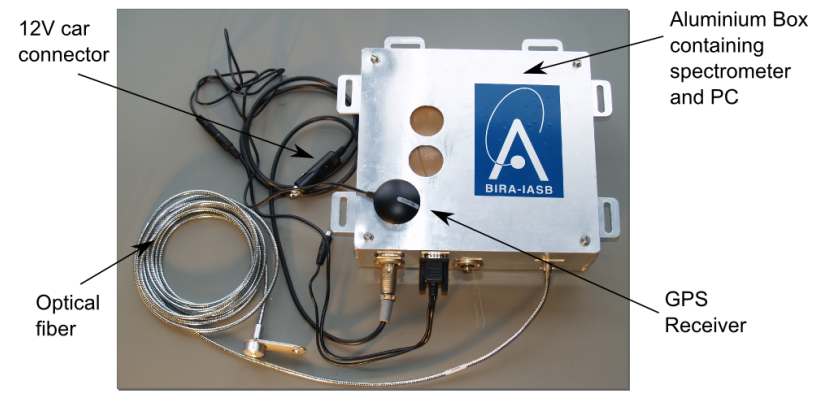

Fig. 2. The ULM-DOAS instrument. Inside the box are a compact UV-Vis spectrometer and a PC-104. Light is collected directly by the optical fiber and a GPS is used to geolocalize the measurements. The whole system is powered with $12 \mathrm{~V}$.

scientists are present, as was the case during the Earth Challenge expedition.

\subsection{The Earth Challenge expedition}

Earth Challenge was a $27000 \mathrm{~km}$ expedition between Australia and Belgium onboard four ultralight aircraft, which took place in April and November 2009 (De Maegd, 2010). The team left from Sydney (Australia) on 5 April 2009 and reached Bangkok (Thailand) on 30 April 2009 with 37 flights. The second stage started from Bangkok, after the monsoon season, on 30 October 2009 and ended after 21 flights in Charleroi (Belgium) on 5 December 2009. The objective of the 7 pilots team, beside reaching Belgium, was to draw the public's attention to major environmental problems, such as sea level rising, pollution and climate change, in cooperation with the World Wildlife Fund (WWF). The project was supported by BIRA-IASB, which used this opportunity to develop and test the new instrument described in the previous section.

The aircraft used were four Coyote RANS-S6. Their cruise speed is $180 \mathrm{~km} \mathrm{~h}^{-1}$ and they can reach an altitude of $4.8 \mathrm{~km}$ with a payload (including pilots) of $300 \mathrm{~kg}$. The range is around $700 \mathrm{~km}$, but additional 501 oil tanks were added for the longest flights of the expedition, e.g. the $874 \mathrm{~km}$ crossing of the Gulf of Oman between Gwadar (Pakistan) and Dubaii (United Arab Emirates).

Figure 3 shows the second part of the expedition superimposed on a monthly-averaged map of GOME-2 $\mathrm{NO}_{2}$ tropospheric measurements during November 2009. The circled numbers correspond to the areas further studied in this work. Except for India and the Po Valley, they correspond to places where few local $\mathrm{NO}_{\mathrm{x}}$ measurements have been reported in the literature. For some of them, e.g. megacities like Karachi and Riyadh, high pollution levels are expected to be found. During the first part, instrument problems prevented the making of measurements after Brisbane (Australia).

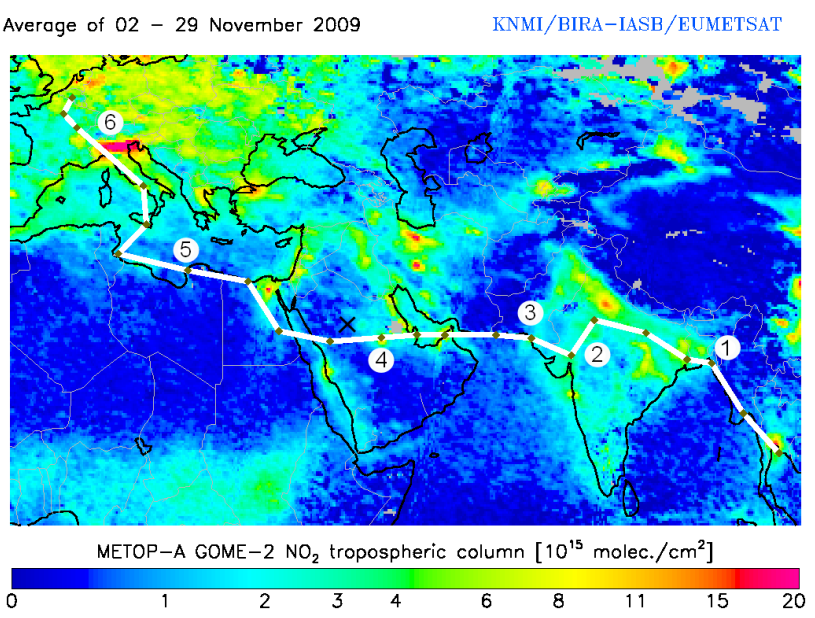

Fig. 3. Flight tracks of the Earth Challenge expedition on a $\mathrm{NO}_{2}$ GOME-2 map. The numbers correspond to the measurements presented in this paper: (1) Chittagong (Bangladesh, 4 November 2009), (2) Rajasthan (India, 15 November 2009), (3) Karachi (Pakistan, 16 November 2009), (4) Riyadh (Saudi Arabia, 24 November 2009), (5) Benghazi (Libya, 27 November 2009), (6) Po Valley (Italy, 2 December 2009). The cross west of Riyadh indicates a sand storm (see Sect. 5.3).

\section{Spectral analysis and $\mathrm{NO}_{2}$ column retrieval}

This section describes the three steps of the data analysis: the DOAS fit, which retrieves integrated concentration along the photon path, the air mass factor calculation used to derive a geophysical interpretation from the DOAS fit, and finally the propagation of the different uncertainties in the error budget.

\subsection{DOAS analysis}

Molecular absorption of $\mathrm{NO}_{2}$ is commonly retrieved in UVvisible atmospheric spectra using the DOAS technique (Platt and Stutz, 2008). This method relies on the fact that, for certain molecules including $\mathrm{NO}_{2}$, the absorption cross-sections vary much more rapidly with wavelength than the scattering effects (Rayleigh and Mie). In practice, a measured spectrum $(I(\lambda))$ is divided by a reference $\left(I_{\text {ref }}(\lambda)\right)$ to remove solar Fraunhofer structures and reduce instrument effects. The slow variations in the logarithm of this ratio are filtered out with a low-order polynomial $(P(\lambda))$, and the remaining absorption structures are fitted in a least-square sense with high-pass filtered laboratory cross-sections $\left(\sigma_{i}^{\prime}(\lambda)\right)$. The equation of DOAS, originating from the Beer-Lambert law, can thus be written as:

$\ln \frac{I(\lambda)}{I_{\mathrm{ref}}(\lambda)}=-\sum_{i} \sigma_{i}^{\prime}(\lambda) \cdot \operatorname{DSCD}_{i}+P(\lambda)$.

In the above equation the index $i$ represents one particular absorber. DOAS analysis results are, for each considered 


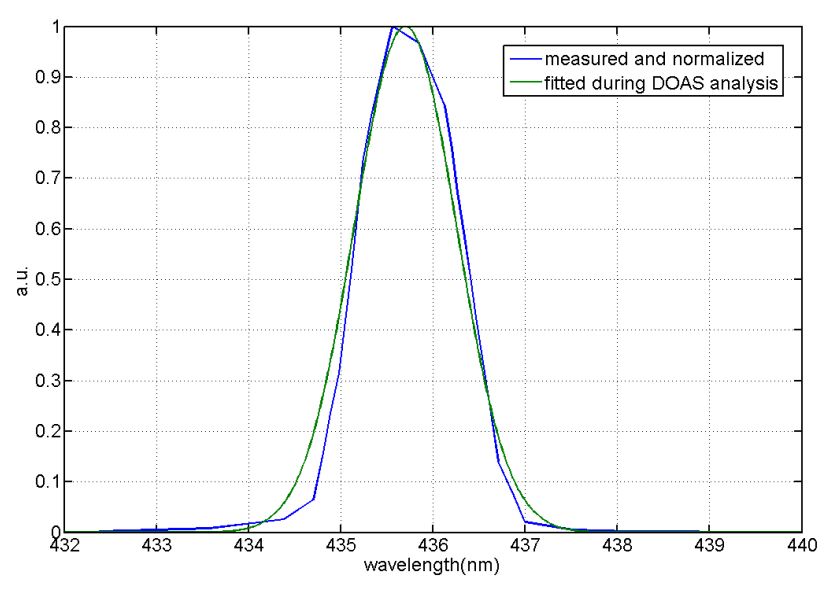

Fig. 4. Slit function measured in the lab using a Hg lamp and fitted from the spectra.

absorber, in the form of differential slant column density (DSCD), i.e. the differences between the concentration integrated along the optical path of the measurement (SCD, slant column density) and the corresponding quantity in the reference spectrum $\left(\mathrm{SCD}_{\mathrm{ref}}\right)$ :

$\mathrm{DSCD}=\mathrm{SCD}-\mathrm{SCD}_{\mathrm{ref}}$.

Table 1 lists the DOAS analysis settings used for the retrieval of $\mathrm{NO}_{2}$ DSCDs. These settings were implemented in the QDOAS software, developed at BIRA-IASB (Fayt et al., 2011). The Ring effect (Grainger and Ring, 1962) is caused by rotational Raman scattering by $\mathrm{O}_{2}$ and $\mathrm{N}_{2}$ and produces a filling-in of solar Fraunhofer lines in scattered light. We fit a Ring pseudo-absorption as described in Chance and Spurr (1997) to take it into account. Additionally, we include an empirical sand cross-section (A. Richter, personal communication, 2011) above desert area (see Sect. 5.3).

Figure 5 presents a typical $\mathrm{NO}_{2}$ DOAS result. The corresponding analyzed and reference spectra originate from the same flight on 2 December 2009, but the former was recorded in the Po Valley while the latter above a clean zone at higher altitude. The first four panels show the simultaneously fitted absorptions of $\mathrm{NO}_{2}$ (panel a), water vapor (panel b), the $\left(\mathrm{O}_{2}\right)_{2}$ collision complex referred to as $\mathrm{O}_{4}$ (panel c), and ozone (panel d) in the form of optical densities relative to the reference spectrum. The lowest panel displays the fit residuals. The four absorbers are clearly detected, and $\mathrm{NO}_{2}$ optical density is particularly high ( $1 \%$ peak-to-peak), which is expected in the Po Valley, one of the most polluted areas in Europe regarding $\mathrm{NO}_{2}$ (see Fig. 3)

\subsection{Air mass factors calculation}

The DOAS analysis per se provides only a qualitative insight into the $\mathrm{NO}_{2}$ field. Indeed, beside being relative to a reference column, a DSCD depends on the light path through the
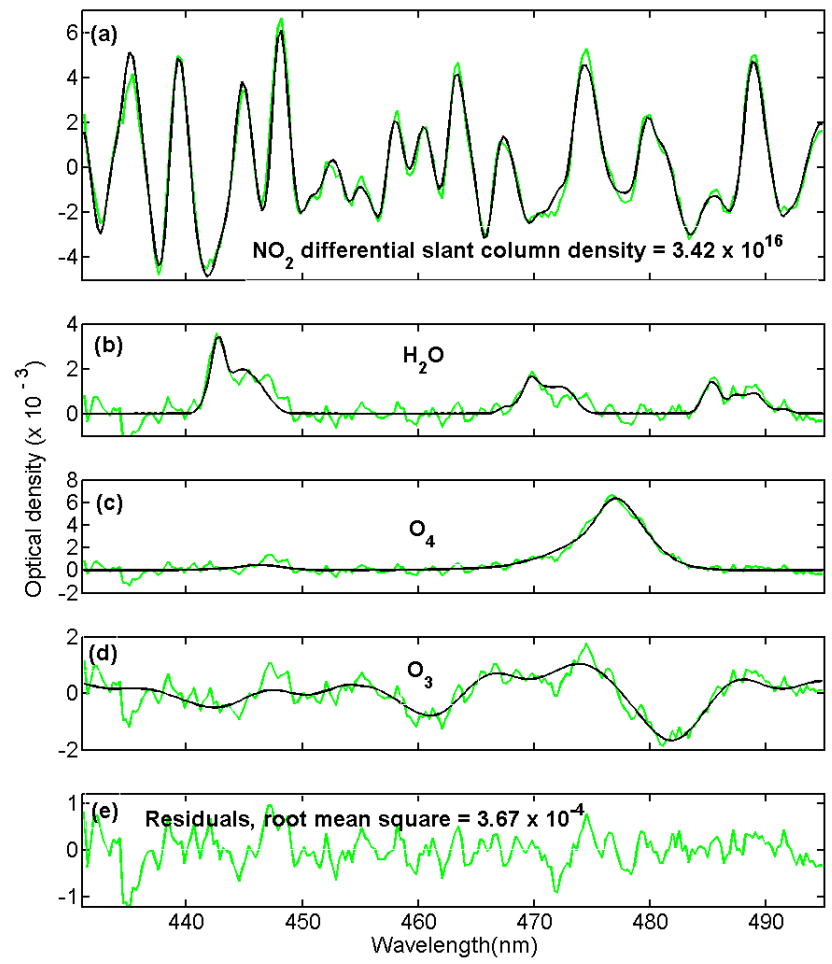

Fig. 5. Example of a DOAS fit; the spectrum was recorded in the Po Valley. Black lines correspond to molecular cross-sections scaled to the detected absorptions in the measured spectrum (green lines).

atmosphere. A more relevant geophysical quantity is the $\mathrm{NO}_{2}$ concentration integrated vertically along the atmosphere, i.e. the $\mathrm{NO}_{2}$ vertical column density (VCD). The air mass factor (AMF) is defined as the ratio between the slant and vertical column densities:

$\mathrm{AMF}=\mathrm{SCD} / \mathrm{VCD}$.

In the following, we describe our assumptions to derive the tropospheric VCD from Eq. (3) and the practical calculations of a tropospheric AMF.

\subsubsection{Assumptions for the tropospheric column retrieval}

As we are interested in the tropospheric vertical column, we split in the following the slant column density in its tropospheric and stratospheric components:

$\mathrm{SCD}=\mathrm{AMF}_{\text {tropo }} \mathrm{VCD}_{\text {tropo }}+\mathrm{AMF}_{\text {strato }} \mathrm{VCD}_{\text {strato }}$.

Using the above expression for the slant column density in Eq. (2) leads to the following formula for the measured DSCD:

$$
\begin{aligned}
\mathrm{DSCD} & =\mathrm{AMF}_{\text {tropo }} \mathrm{VCD}_{\text {tropo }}+\mathrm{AMF}_{\text {strato }} \mathrm{VCD}_{\text {strato }} \\
& -\left(\mathrm{AMF}_{\text {tropo }_{\text {ref }}} \mathrm{VCD}_{\text {tropo }_{\text {ref }}}+\mathrm{AMF}_{\text {strato }_{\text {ref }}} \mathrm{VCD}_{\text {strato }_{\text {ref }}}\right) .
\end{aligned}
$$


Table 1. DOAS analysis settings.

\begin{tabular}{ll}
\hline Fitting window & $431-495 \mathrm{~nm}$ \\
\hline $\mathrm{NO}_{2}$ & Vandaele (1998) \\
$\mathrm{O}_{4}$ & Hermans \\
& http://www.aeronomie.be/spectrolab/o2.htm \\
$\mathrm{H}_{2} \mathrm{O}$ & Harder and Brault (1997) \\
$\mathrm{O}_{3}$ & Burrows et al. (1999) \\
Ring & Chance and Spurr (1997) \\
Polynomial order & 3 \\
\hline
\end{tabular}

Equation (5) may be simplified if the reference spectrum is well chosen. Due to its short lifetime in the troposphere, $\mathrm{VCD}_{\text {tropo }_{\text {ref }}}$ column can be assumed to be null far enough from the $\mathrm{NO}_{2}$ emission sources, e.g. above the deserts or the oceans. If on the other hand the reference spectrum is taken the same day when the Sun is high enough, stratospheric contributions cancel each other, since the stratospheric $\mathrm{NO}_{2}$ is slowly varying during the day and the stratospheric AMF is constant. Equation (5) can be thus approximated as:

$$
\mathrm{DSCD}=\mathrm{AMF}_{\text {tropo }} \cdot \mathrm{VCD}_{\text {tropo }}
$$

From Eq. (6) it is possible to retrieve $\mathrm{VCD}_{\text {tropo }}$, assuming independence between a given $\mathrm{AMF}_{\text {tropo }}$ and $\mathrm{VCD}_{\text {tropo }}$. This is usually done and implies that the $\mathrm{NO}_{2}$ loading is optically thin enough that it does not influence the radiative transfer. The resulting AMF still depends then on the $\mathrm{NO}_{2}$ profile but not on its absolute value. We use this hypothesis and check its validity in the next section, where we detail the practical $\mathrm{AMF}_{\text {tropo }}$ calculation.

\subsubsection{Radiative transfer and assumptions on $\mathrm{NO}_{2}$ and aerosol extinction profiles}

The radiative transfer model used in this study is UVspec/DISORT (Mayer and Kylling, 2005). It is based on the discrete ordinate method and deals with multiple scattering in a pseudo-spherical approximation. Given the wavelength, the observation's geometry relative to the Sun and the atmospheric state, the model calculates the scattered radiance and the absolute slant column density (SCD) of molecular absorbers. It is thus possible to derive $\mathrm{AMF}_{\text {tropo }}$ from Eq. (3). Setting a grid $10 \mathrm{~km}$ high, we neglect the stratospheric contribution as discussed in the previous section.

Considering the DOAS fitting window (see Sect. 3.1), calculations are done at $460 \mathrm{~nm}$. The GPS data recorded with the spectra allow for an accurate calculation of the Sun's position and the aircraft's heading. To take into account the numerical aperture of the optical fiber, each SCD is the weighted mean of 13 SCDs at uniformly distributed angles between -12 and 12 degrees around the horizon. The weights correspond to the different radiances calculated in the respective intermediate SCD geometries.

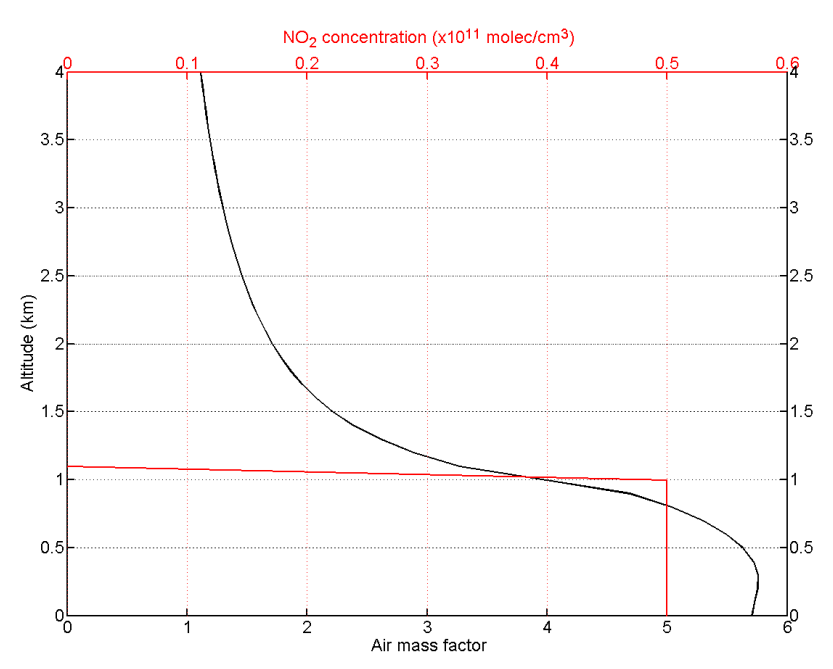

Fig. 6. Air mass factor versus altitude (black) for an idealized $\mathrm{NO}_{2}$ tropospheric profile (red) well mixed in the boundary layer and of negligible concentration in the free troposphere. The calculations were done at $460 \mathrm{~nm}$, setting an albedo of 0.1 , a relative azimuth and solar zenith angle of 90 and $45^{\circ}$, respectively, and a surface visibility of $20 \mathrm{~km}$.

The $\mathrm{NO}_{2}$ and aerosol profiles in the model both correspond to a well-mixed boundary layer and negligible concentrations and extinction in the free troposphere (for the $\mathrm{NO}_{2}$, see Fig. 6). The boundary layer heights are interpolated from ECMWF (European Centre for Medium-Range Weather Forecasts) forecasts at the time and heights of the measurements, except for Riyadh (see Sect. 5.1). In clean areas, these assumptions may not be realistic enough, as we showed in a previous airborne experiment in the Arctic (Merlaud et al., 2011), where we detected a $\mathrm{NO}_{2}$ layer in the free troposphere. On the other hand, in urban areas, larger concentrations are found close to the ground than higher up in the boundary layer (Dieudonné, 2012). The measurements presented in this study were recorded in polluted zones but not directly above cities. Considering $\mathrm{NO}_{2}$, Heland et al. (2002) studied the effect of the profile's shape comparing aircraft in-situ and OMI data, concluding that it was relatively weak. Boersma et al. (2009) also assumed a homogeneous boundary layer to compare in-situ surface $\mathrm{NO}_{2}$ concentrations with SCIAMACHY (SCanning Imaging Absorption SpectroMeter for Atmospheric CartograpHY) and OMI columns. This is also confirmed by the few tropospheric $\mathrm{NO}_{2}$ lidar measurements available (Volten et al., 2009). Considering aerosol extinction, the many lidar profiles available in polluted zones (e.g. Landulfo et al., 2003; Guibert et al., 2005) indicate a maximum extinction in the boundary layer, even if the shape is less step-like. In practice, we derive aerosol optical thickness at $550 \mathrm{~nm}$ from MODIS (MODerate-resolution Imaging Spectroradiometer) (retrieved from Giovanni (GESDISC Interactive Online Visualization ANd aNalysis Infrastructure), Acker and Leptoukh, 2007) and divide it by the 


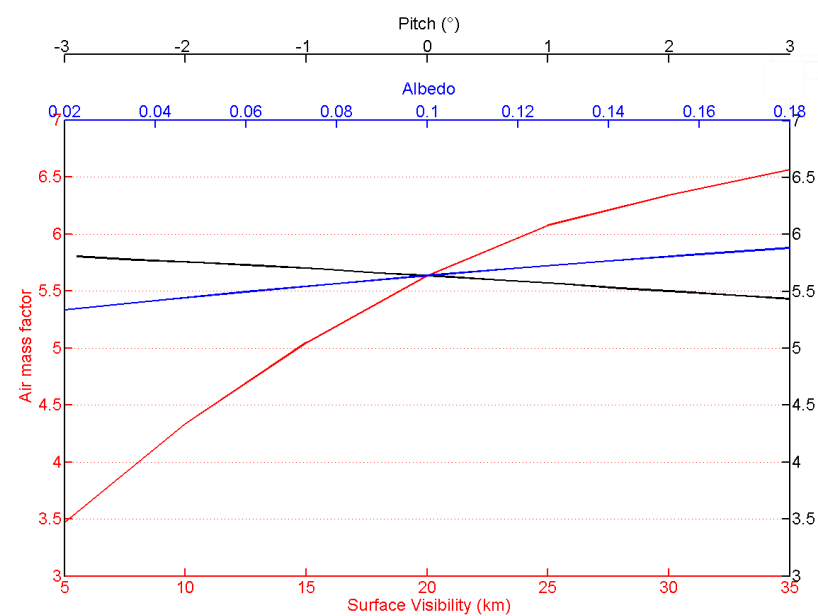

Fig. 7. Air mass factor versus surface visibility (red), albedo (blue) and pitch angle (black). The last two parameters only have small effects due to the limb observation geometry and the large field of view, respectively. The calculations were done at $460 \mathrm{~nm}$ for an altitude of $0.5 \mathrm{~km}$, setting a relative azimuth and solar zenith angle of $90^{\circ}$ and $45^{\circ}$, respectively, and with a $1 \mathrm{~km}$ thick homogeneous boundary layer.

BLH (boundary layer height) to get the extinction coefficient. We then scale this extinction coefficient at $460 \mathrm{~nm}$ using the Angstrom coefficient as described in Nebuloni (2005), and derive visibility at this wavelength from the Koschmieder law (Koschmieder, 1926). The same approach to estimate the visibility will be used for the GEOS-R satellite (NOAANESDIS, 2010).

Figure 6 shows the variation of the AMF with the observation's altitude for the idealized profile considered in the model. In the calculations, the solar zenith angle was $45^{\circ}$, the visibility $20 \mathrm{~km}$, and the albedo 0.1 . These numbers are representative of the conditions of the campaign. The AMF and thus the sensitivity are maximum when the aircraft flies at $500 \mathrm{~m}$ altitude, where the AMF is around 5.6. The AMF then decreases sharply when the plane crosses the boundary layer. This indicates that this parameter is important for the accuracy of our measurements.

Figure 6 also indicates the typical horizontal resolution of our measurements, directly related to the product of the AMF and the boundary layer height with our assumptions on the profile. Flying inside the $\mathrm{NO}_{2}$ layer, the horizontal resolution is close to $5 \mathrm{~km}$. This rather large number arises from the limb geometry.

For the retrievals, air mass factors are interpolated in lookup tables calculated for each flight around the places of interest (see Fig. 3). The parameters in the look-up tables are aircraft's altitude, relative azimuth, solar zenith angle, boundary layer height, visibility, and albedo. For a given flight, the first three parameters vary according to the GPS data, while the last three are set constant.

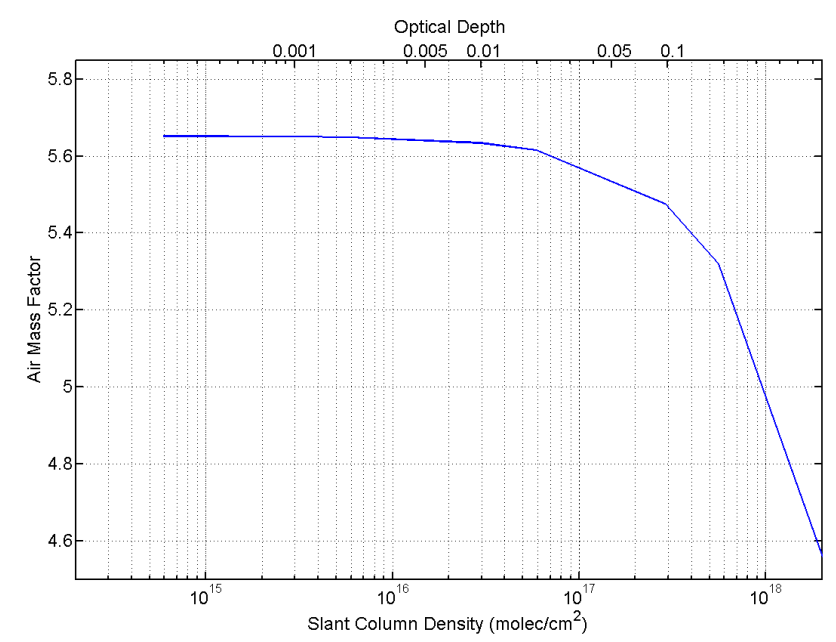

Fig. 8. Air mass factor versus slant column density. $\mathrm{NO}_{2}$ loading starts to influence significantly the radiative transfer above $5 \times 10^{16}$ molec $\mathrm{cm}^{-2}$. The calculations were done at $460 \mathrm{~nm}$ for an altitude of $0.5 \mathrm{~km}$, setting a relative azimuth and solar zenith angle of $90^{\circ}$ and $45^{\circ}$, respectively, and with a $1 \mathrm{~km}$ thick homogeneous boundary layer.

\section{Sensitivity studies and error analysis}

Figure 7 shows the variation of the air mass factor for the visibility, pitch angle and albedo in the typical ranges of the flights. Surface visibility plays the largest role in the AMF variation, which is understandable from the limb geometry of our measurements. For the same reason, albedo very weakly affects the air mass factor. Indeed, most of the detected photons are scattered before reaching the ground, as illustrated in Fig. 1, and thus not affected by its reflectivity. This is very different from nadir-looking satellites, for which the albedo uncertainty matters much more in the final error budget, as can be seen in Boersma et al. (2004). Finally, the small effect of the pitch angle is due to the large field of view: the multiple lines of sight smooth the variation in aircraft attitude.

Figure 8 displays an effect that is often neglected in DOAS studies, i.e. the influence of the studied absorber on the radiative transfer and thus the AMF itself. When the absorber's column, in our case $\mathrm{NO}_{2}$, is high enough, it can not be considered as optically thin and reduces the air mass factor. The effect is visible from $5 \times 10^{16}$ molec $\mathrm{cm}^{-2}$, corresponding to an optical density of 0.02 . We believe this error should be considered when accurate error budgets are necessary, since it could play a larger role than the cross-section uncertainties, for instance, which are often taken into account. In particular, low-elevation MAX-DOAS (multiple-axis DOAS) measurements in polluted regions are likely to be affected by this error.

Table 2 indicates the uncertainties considered in this study and their effect on the relative air mass factor. The accuracy 
Table 2. Error contributions to the air mass factor (AMF).

\begin{tabular}{llc}
\hline & $\Delta$ parameters & $\frac{\Delta \mathrm{AMF}}{\mathrm{AMF}}$ \\
\hline Boundary layer height & $300 \mathrm{~m}$ & $15 \%$ \\
Visibility & $6 \mathrm{~km}$ & $12 \%$ \\
Correlation between & & \\
BLH and visibility & 0.95 & $14 \%$ \\
Pitch & $2^{\circ}$ & $2 \%$ \\
SCD & $5 \times 10^{14}{\text { molec } \mathrm{cm}^{-2}}^{-2}$ & $1 \%$ \\
Albedo & 0.05 & $1 \%$ \\
\hline
\end{tabular}

of the ECMWF boundary layer heights was investigated by Palm et al. (2005), who concluded that the BLH were 200$400 \mathrm{~m}$ underestimated. We thus consider an error of $300 \mathrm{~m}$ for this parameter. This is the major source of error in our measurements, leading to $15 \%$ uncertainty on the AMF. Considering the albedo, Kleipool et al. (2008) derived an absolute uncertainty of 0.01 to 0.02 for the OMI albedo used in our AMF calculation. We use 0.05 , as this parameter's role is not critical anyway ( $1 \%$ on AMF). The uncertainty in the visibility is set to $6 \mathrm{~km}$. This value originates from the propagation in Koschmieder's law of the 300 m uncertainty for the BLH already mentioned and a typical uncertainty of 0.1 for the AOT (aerosol optical thickness), which we derive from a comparison between MODIS Aqua and CALIPSO (CloudAerosol Lidar and Infrared Pathfinder Satellite Observations) (Kittaka et al., 2011). Finally, the error due to the effect of $\mathrm{NO}_{2}$ on the radiative transfer leads to $1 \%$ uncertainty on the AMF, a small effect, but comparable to the errors due to the pitch and the albedo.

In practice, the error on the tropospheric column is derived from Eq. (6) as:

$\sigma_{\mathrm{VCD}_{\text {tropo }}}=\sqrt{\left(\frac{\sigma_{\mathrm{DSCD}}}{\mathrm{AMF}}\right)^{2}+\sigma_{\mathrm{AMF}}^{2}\left(\frac{\mathrm{DSCD}}{\mathrm{AMF}^{2}}\right)^{2}}$

In this equation, the error on the DSCD ( $\left.\sigma_{\mathrm{DSCD}}\right)$ is an output of the DOAS analysis (Fayt et al., 2011). The error on the AMF is the quadratic sum of the different errors discussed previously. Note that we take into account the correlation between the boundary layer height and the visibility, introducing an adequate term in Table 2. The correlation coefficient is estimated from the values of the BLH and visibility in Table 3 .

\section{Results}

This section presents the results for the flights of Fig. 3. We first compare our measurements with satellite data (OMI and GOME-2) for the flights when these are available at the locations of our flights, and indicate the $\mathrm{NO}_{2}$ loading above other interesting hot spots. Then, we demonstrate that our measurements are suitable to estimate a flux for an isolated point

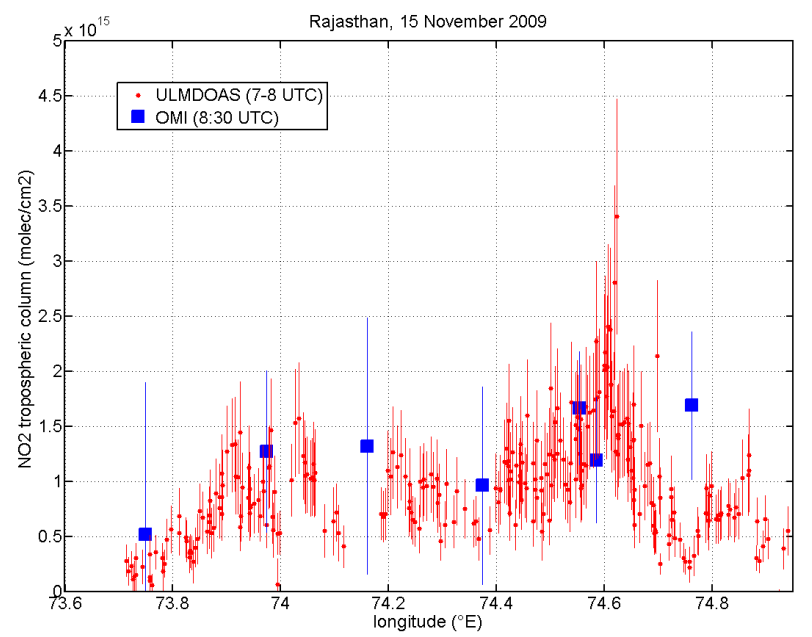

Fig. 9. ULM-DOAS (red) and OMI (blue) measurements over Rajasthan, India (15 November 2009). ULM-DOAS data were recorded between 07:26 and 08:47 UTC and cover the latitude range from $25.79^{\circ}$ to $24.39^{\circ}$. The $\mathrm{NO}_{2}$ field is rather uniform.

source like Riyadh. Finally, we confirm a soil signature in the spectra that closely matches results from a previous study on satellite data (Richter et al., 2011).

\subsection{Comparisons with satellites}

Figures 9, 10, and 11 compare OMI (DOMINO (Dutch $\mathrm{OMI} \mathrm{NO}_{2}$ ) version 2.0, Boersma et al., 2011) and GOME-2 (TM4NO2A version 2.1, Boersma et al., 2004) data with our ULM-DOAS measurements, above Rajasthan (15 November 2009), the Po Valley (2 December 2009), and Saudi Arabia (24 November 2009). The flight conditions are detailed in lines 2, 6, and 4 of Table 3, respectively. These three areas represent an interesting sample of the global tropospheric $\mathrm{NO}_{2}$ field above land. Indeed, the first two areas indicate rather homogeneous tropospheric $\mathrm{NO}_{2}$ loadings, but absolute values are one order of magnitude higher in the Po Valley than in Rajasthan. In Saudi Arabia, the situation is very different, since one megacity, Riyadh, is surrounded by desert with very few $\mathrm{NO}_{2}$ sources. This yields high columns close to the city, rapidly decreasing to reach negligible values further away above the desert.

The agreement between ULM-DOAS and satellite data is qualitatively good for the three days, but better quantitatively above Rajasthan and Italy than above Saudi Arabia. Above Rajasthan (Fig. 9), the tropospheric $\mathrm{NO}_{2}$ columns seen from the aircraft span from $0.1 \pm 0.1$ to $3 \pm 1 \times 10^{15} \mathrm{molec} \mathrm{cm}^{-2}$, whereas from OMI $0.5 \pm 0.6$ to $1.7 \pm 1 \times 10^{15} \mathrm{molec} \mathrm{cm}^{-2}$. This discrepancy might be explained by a dilution effect; indeed OMI is not able to resolve spatial structures at scales smaller than $20 \mathrm{~km}$. Most of the points are, however, inside the error bars. Considering the Po Valley (Fig. 10), OMI data are unfortunately affected by the row anomaly 

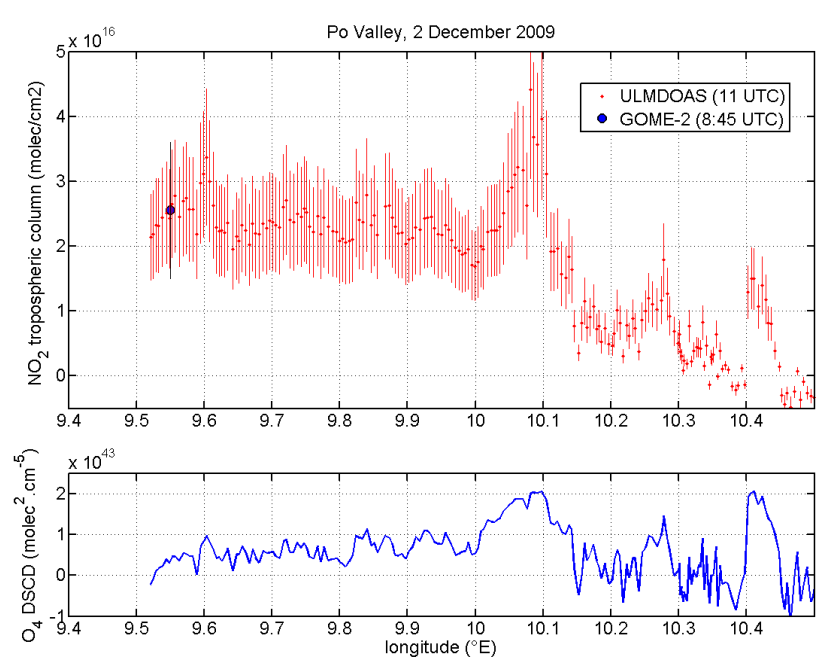

Fig. 10. ULM-DOAS (red) and GOME-2 (blue) measurements over Italy (2 December 2009). ULM-DOAS data were recorded between 10:29 and 12:14 UTC and cover the latitude range from $44.58^{\circ}$ to $45.54^{\circ}$. The zone west of $10^{\circ} \mathrm{E}$ is the Po Valley.

(Boersma et al., 2011), but the GOME-2 measurement and our airborne measurements are very close, around $2.6 \pm 0.6 \times$ $10^{16}$ molec $\mathrm{cm}^{-2}$. Note that the two peaks at longitude $10.1^{\circ}$ and $10.4^{\circ} \mathrm{E}$ are coincident to $\mathrm{O}_{4}$ DSCD higher values and are thus probably due to enhancement in the light path owing to scattering in clouds.

Figure 11 indicates a positive bias between ULM-DOAS measurements and satellite data in the region where the $\mathrm{NO}_{2}$ columns are highest. In the case of GOME-2, this can be explained by the dilution effect considering the size of the pixels, and partly by the $3 \mathrm{~h}$ time difference. Considering OMI data, these effects are expected to be much smaller, since the two measurements are almost simultaneous and the spatial resolution of OMI is much better than GOME-2. For this area, standard MODIS Aqua data are not available and we had to use the MODIS Deep blue product AOT, i.e. 0.2, to estimate the visibility. There is an Aeronet station close to Riyadh (Sabbah and Hasan, 2008), but the data set is discontinuous for the period of the flight, and the only AOT measurement point, 0.45, leads to a reduced AMF and thus an even higher bias between our measurements and OMI. Note that offsets could also originate from an error in the boundary layer height, which is close to the observation altitude (see Table 3), or from a non-negligible part of the AOT in the free troposphere. The latter would increase the AMF for the ULM-DOAS measurements, while simultaneously reducing the satellite AMF, thus partly reducing the observed bias. For this area only, we use the GDAS (Global Data Assimilation System) archived boundary layer height instead of the ECMWF, which is surprisingly low for this day and leads to even larger discrepancies between OMI data and our measurements. This persistent bias and the fact that no validation

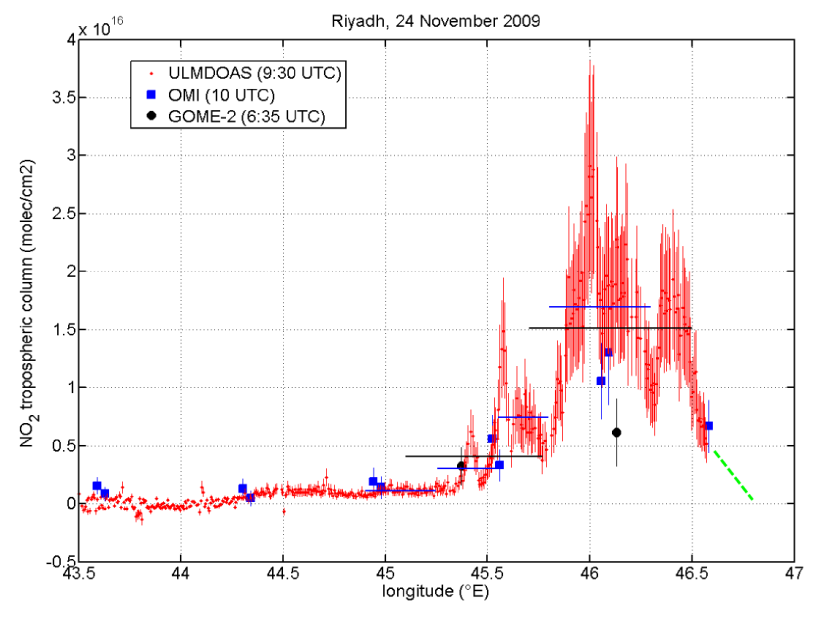

Fig. 11. ULM-DOAS (red), OMI (blue), and GOME-2 (black) measurements over Saudi Arabia (24 November 2009). ULM-DOAS data were recorded between 09:07 and 12:03 UTC and cover the latitude range from $25.18^{\circ}$ to $24.79^{\circ}$. Horizontal blue and black lines correspond to ULM-DOAS data averaged over OMI and GOME-2 pixel extensions, respectively. ULM-DOAS tropospheric $\mathrm{NO}_{2}$ measurements are larger in this case than the ones seen by both satellites.

has been achieved, to our knowledge, over deserts leads us to point out the necessity of other measurements to check for a possible underestimation of OMI data in similar areas.

Figure 12 helps to interpret the patterns seen in the pink box of Fig. 11. It presents the OMI pixels around Riyadh, superimposed on a map with Riyadh extent, the main wind direction retrieved from GDAS and the ULM-DOAS flight track. The color code is the same for OMI and ULM-DOAS data. The megacity occupies an area slightly smaller than three OMI pixels, and the aircraft was flying $70 \mathrm{~km}$ northwest of it when it detected the highest $\mathrm{NO}_{2}$ columns. ULMDOAS and OMI data are both understandable from the wind direction as a pollution plume of the city, which would have, compared to this source, a relatively similar horizontal extent. It is thus possible to calculate the $\mathrm{NO}_{2}$ flux, integrating horizontally the column and then multiplying by the projection of the wind vector on the normal to the flight track. Such a calculation leads to a flux of around $140 \mathrm{~mol} \mathrm{~s}^{-1}$. Note that to obtain this value, we added the ghost part of the plume west of $46.7^{\circ} \mathrm{E}$, depicted in green in Fig. 11. Due to that and the wind uncertainties, we find it difficult to estimate the associated error. Nethertheless, the value is relatively close to the one derived by Beirle et al. (2011) from satellite, i.e. $187 \pm 14 \mathrm{~mol} \mathrm{~s}^{-1}$. This points out that, providing accurate wind data, our instrument would be useful to estimate flux from megacities. This has been done from cars (e.g. Johansson et al., 2009), but an aircraft covers an exhaust plume in a much shorter time and is thus less sensitive to temporal variations of the $\mathrm{NO}_{2}$ field. 
Table 3. Conditions and results of the campaign. See Fig. 3 for the places and dates of the measurements. We give the main parameters for calculating the air mass factor (AMF), i.e. the surface visibility (Vis.), the solar zenithal angles (SZA) and relative azimuth (rel Az.), the boundary layer height (BLH), the albedo (Alb.) and the altitude of the aircraft (Alt.). The tropospheric column (VCD tropo) is the typical value found while overflying the areas.

\begin{tabular}{lrrrrrrrlr}
\hline Meas. & $\begin{array}{r}\text { Vis. } \\
(\mathrm{km})\end{array}$ & $\begin{array}{r}\text { SZA } \\
\left({ }^{\circ}\right)\end{array}$ & $\begin{array}{r}\text { rel Az. } \\
\left({ }^{\circ}\right)\end{array}$ & $\begin{array}{r}\text { BLH } \\
(\mathrm{km})\end{array}$ & $\begin{array}{r}\text { Alb. } \\
(\%)\end{array}$ & $\begin{array}{r}\text { Alt. } \\
(\mathrm{km})\end{array}$ & AMF & $\begin{array}{l}\mathrm{VCD}_{\text {tropo }} \\
\left(\mathrm{molec} \mathrm{cm}^{-2}\right)\end{array}$ & $\begin{array}{r}\text { Conc. } \\
\left(\mu \mathrm{g} \mathrm{m}^{-3}\right)\end{array}$ \\
\hline 1 & $\mathrm{n} / \mathrm{a}$ & 38 & 140 & 1.3 & 6 & 0.3 & $\mathrm{n} / \mathrm{a}$ & n/a & $\mathrm{n} / \mathrm{a}$ \\
2 & 24 & $45-51$ & 16 & 2.1 & 10 & 0.6 & 4.4 & $0.25 \pm 0.8 \times 10^{16}$ & 1 \\
3 & 20 & 59 & 25 & 1.6 & 11 & 0.15 & 4.9 & $2.4 \pm 0.8 \times 10^{16}$ & 10 \\
4 & 15 & $46-64$ & 70 & 1.1 & 14 & 1.25 & 2.1 & $2 \pm 0.6 \times 10^{16}$ & 15 \\
5 & 23 & 57 & 125 & 1.5 & 8 & 0.5 & 5.8 & $2.3 \pm 0.8 \times 10^{16}$ & 10 \\
6 & 10 & 67 & 145 & 0.4 & 6 & 0.65 & 2.1 & $2.2 \pm 0.8 \times 10^{16}$ & 40 \\
\hline
\end{tabular}

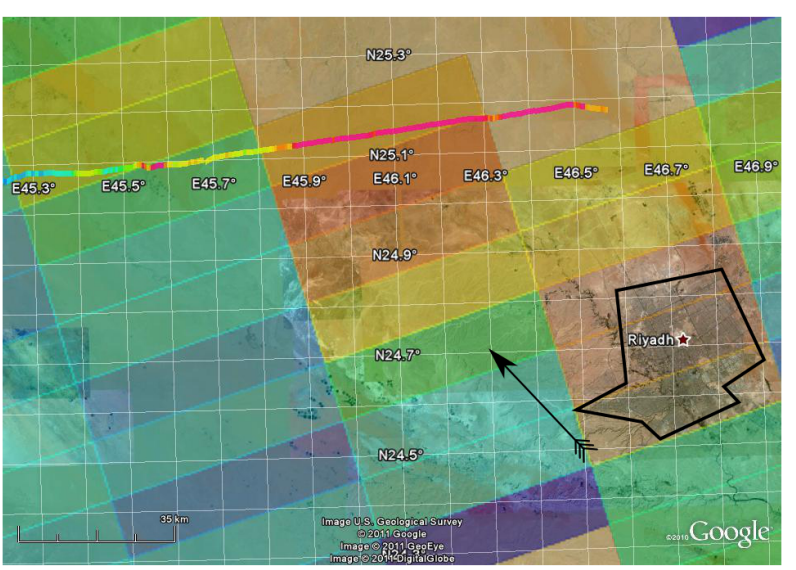

$\mathrm{NO}_{2}$ tropospheric column $\left[\times 10^{15} \mathrm{molec} . / \mathrm{cm}^{2}\right]$

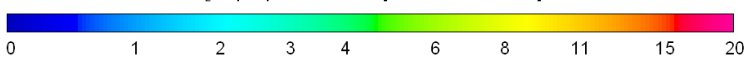

Fig. 12. Map of Riyadh surrounding, with ULM-DOAS and OMI $\mathrm{NO}_{2}$ data superimposed. Riyadh agglomeration is delimited by the black polygon. The arrow indicates the wind direction according to the GDAS archive.

\subsection{Other interesting measurements}

Table 3 summarizes the main results of the campaign and the conditions of the measurements. The numbers representing the measurements are related to Fig. 3. We do not estimate the uncertainty on the mass concentration, which would be correlated to the uncertainty on the boundary layer height, because even if our measurements have a finer spatial resolution than satellites, the real $\mathrm{NO}_{2}$ field can be much more heterogeneous than seen by our instrument. These considerations also apply to our measured vertical columns, but they are less relevant in the context of comparing with satellite data.

In addition to the measurements described in the previous section, we report the measured $\mathrm{NO}_{2}$ tropospheric column close to three large cities, Chittagong (1), Karachi (3) and Benghazi (5). The latter two are usually visible from OMI

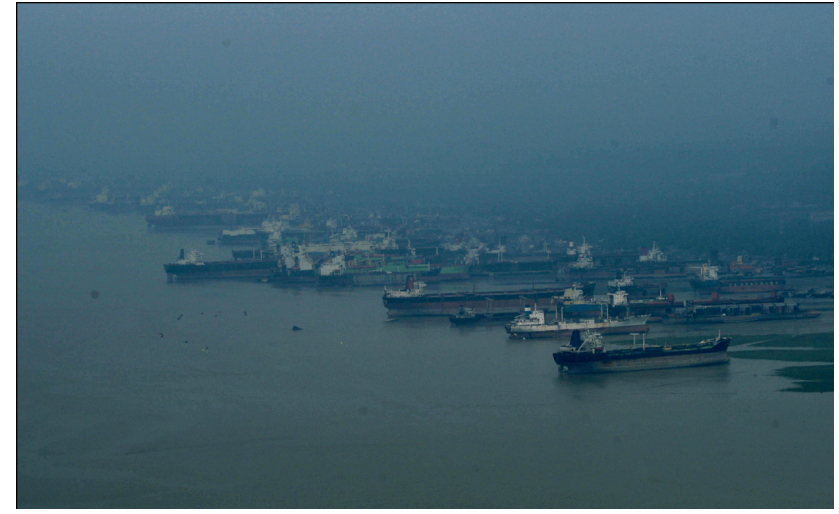

Fig. 13. Picture of Chittagong ship cemetery taken during the expedition. The visibility is obviously low. Courtesy of Michel de Maegd.

and the corresponding MODIS Aqua AOT is available for both. Karachi is one of the largest cities in the world regarding population (15 million inhabitants). We estimate the tropospheric $\mathrm{NO}_{2}$ column during the landing on an airport $15 \mathrm{~km}$ east of the city center to be $2.4 \pm 1 \times 10^{16} \mathrm{molec}^{-2}$. Benghazi is a comparatively much smaller city. Nevertheless we also detected high $\mathrm{NO}_{2}$ loadings there, around $2.3 \pm$ $0.8 \times 10^{16} \mathrm{molec}^{-2}$. Such high columns are certainly linked to the industries of the city and particularly to its refineries.

Figure 13 is a picture taken by the pilots during the campaign, while flying above Chittagong. It shows one of the city's main industries, i.e. one of the largest ship cemeteries in the world. The picture coincided with high measured slant columns, around $4 \times 10^{16}$ molec $\mathrm{cm}^{-2}$. However, we did not convert these values to vertical columns, since no AOT data were available for the day of the flight. It is, however, obvious from the picture that the visibility is quite small, probably under $5 \mathrm{~km}$. This probably results from a combination of a heat fog and of aerosols from the city. Therefore we can 


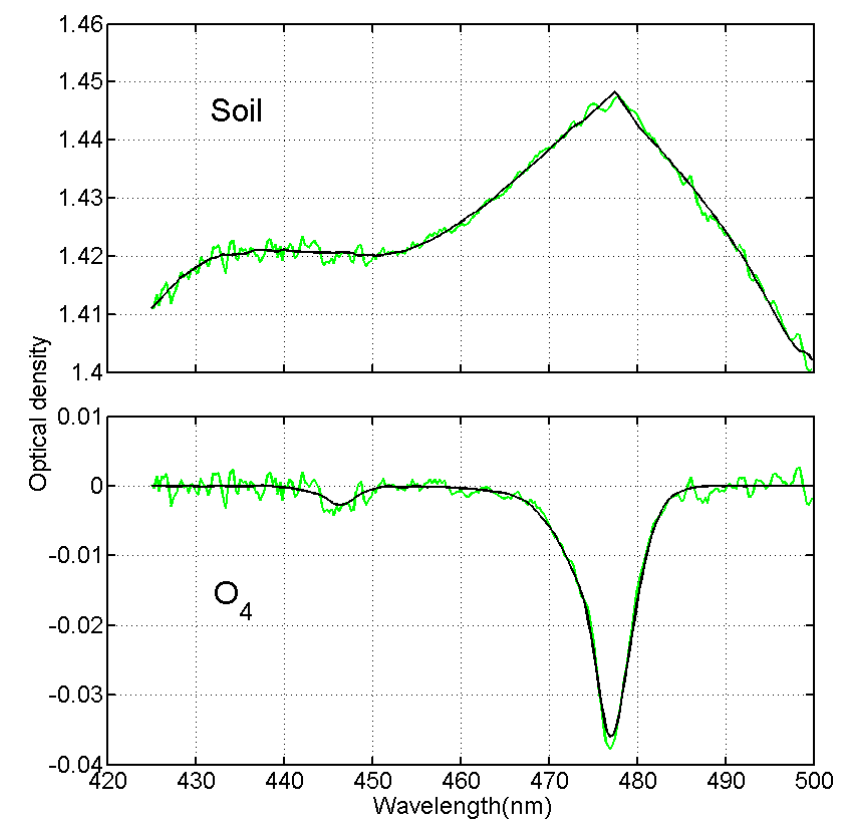

Fig. 14. Soil signature in the spectra over the Arabian desert (upper panel). For comparison, the $\mathrm{O}_{4}$ signature is displayed in the lower panel.

expect the AMF to be very small, which suggests that the $\mathrm{NO}_{2}$ pollution was probably very high in this region.

\subsection{Soil signature above desert}

Richter et al. (2011), while improving GOME-2 $\mathrm{NO}_{2}$ retrieval, empirically derived a soil signature visible in the spectra corresponding to desert areas. The inclusion of this signature yielded an improvement in the DOAS fit, mostly visible in regions with bare soils, e.g. the Sahara and the Arabic peninsula. Richter et al. (2011) also found a similar spectral shape in a lab experiment using sand. They nevertheless pointed out that more measurements were necessary to solidly confirm the attribution to a soil effect, particularly due to possible correlations with $\mathrm{O}_{4}$.

Figure 14 shows the fit of the soil signature (A. Richter, personal communication, 2011) together with $\mathrm{O}_{4}$ in a spectrum recorded above Saudi Arabia on 24 November 2009. The DOAS settings, except for the fitting window, are given in Table 1. The reference spectrum was recorded in Italy on 2 December 2009, which leads to a larger signal of the soil signature than using a reference spectrum from Saudi Arabia. This is understandable if the signature really originates from bare soil, which is present all along the flight on 24 November 2009, and thus in all the spectra, but not in Italy.

Figure 15 displays the time series of the DOAS fit results for the soil signature (upper panel) and the RMS (root mean square) fit with and without the soil signature (lower panel). Several episodes of enhanced soil signal are visible,

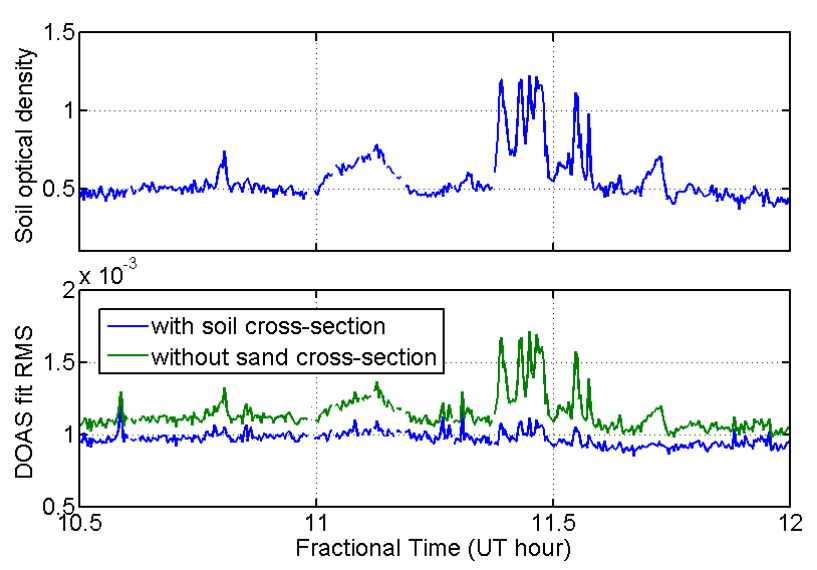

Fig. 15. Time series of the soil signature signal (upper panel) and root mean square of the DOAS fit (lower panel), with (blue curve) and without (green curve) the soil signature in the fit. The spectra were recorded above Saudi Arabia when the pilots reported their crossing of a sand storm.

the largest one just before 11:30 UTC. In the lower panel we see that these episodes appear as increased RMS time series if the DOAS fit does not include the soil signature (green curve). If the soil signature is taken into account (blue curve), the RMS is relatively constant over the flight.

The episodes just discussed are coincident with a sand storm that was reported by the pilots while approaching Medina. This reinforces our confidence that the soil signature identified by Richter et al. (2011) has indeed a geophysical origin, and that it can be detected on suspended sand particles. Using a reference spectrum recorded over the Gulf of Oman to analyze other flight spectra, we detected smaller low visibility episodes associated with soil signature in Rajasthan, Egypt and Pakistan, but not over Italy. Note that the soil signature, due to its broad-band structure, is partly hidden in the DOAS fit using a higher order polynomial.

\section{Conclusions}

We presented a new airborne instrument designed for tropospheric $\mathrm{NO}_{2}$ column measurement, the ULM-DOAS. It was operated during the Earth Challenge expedition, which took place in 2009 between Australia and Belgium. The ULMDOAS was designed to fit onboard the ultralight aircraft of the expedition and to be fully automatic. The set-up is simple without any attitude stabilization, and related uncertainties are minimized by the use of a large field of view. The limb geometry of the instrument makes it suitable for low-flying aircraft and maximizes the sensitivity to boundary layer $\mathrm{NO}_{2}$.

Measurements during the Earth Challenge expedition are consistent with OMI and GOME-2 data and are interesting on their own, since very few validation campaigns were performed in the countries overflown. Highest 
$\mathrm{NO}_{2}$ loadings were detected above megacities such as Karachi $\left(2.4 \pm 0.8 \times 10^{16}\right.$ molec $\left.\mathrm{cm}^{-2}\right)$ or Benghazi $(2.3 \pm$ $0.8 \times 10^{16}$ molec $\mathrm{cm}^{-2}$ ). Our measurements also confirm the recent finding of a soil signature above desert.

Compared to satellite data, our instrument is able to detect higher spatial frequency patterns in the $\mathrm{NO}_{2}$ field (around 5 $\mathrm{km}$ compared with an OMI pixel width of $13 \mathrm{~km}$ ). We believe it is well suited for tropospheric $\mathrm{NO}_{2}$ column validation, offering a low-cost alternative to larger aircraft measurements. Such measurements are also well suited for flux measurements from extended sources, providing accurate wind data. The measurement accuracy would benefit from the addition of a compact PTU (pressure, temperature, relative humidity) sensor, indicating the aircraft position relative to the boundary layer, and of a small lidar to accurately measure simultaneously the extinction profile.

Acknowledgements. This work was supported by the Belgian Ministry of Scientific research. We are grateful to Tom Egerickx, Marc Nevens, and Geert Hemerijckx from our mechanical workshop and to the Earth Challenge team and particularly Michel de Maegd. We also thank Andreas Richter for providing his sand spectral signature, and François Hendrick, Gaia Pinardi, and Lori Neary for useful discussions.

Edited by: U. Friess

\section{References}

Acker, J. G. and Leptoukh, G.: Online analysis enhances use of NASA Earth science data, Eos T. Am. Geophys. Un., 88, p. 14, doi:10.1029/2007EO020003, 2007.

Beirle, S., Boersma, K. F., Platt, U., Lawrence, M. G., and Wagner, T.: Megacity Emissions and Lifetimes of Nitrogen Oxides Probed from Space, Science, 333, 1737-1739, doi:10.1126/science.1207824, 2011.

Boersma, K. F., Eskes, H. J., and Brinksma, E. J.: Error analysis for tropospheric $\mathrm{NO}_{2}$ retrieval from space, J. Geophys. Res., 109, D04311, doi:10.1029/2003JD003962, 2004.

Boersma, K., Jacob, D., Bucsela, E., Perring, A., Dirksen, R., van der A, R., Yantosca, R., Park, R., Wenig, M., Bertram, T., and Cohen, R.: Validation of OMI tropospheric NO2 observations during INTEX-B and application to constrain NOx emissions over the eastern United States and Mexico, Atmos. Environ., 42, 4480-4497, doi:10.1016/j.atmosenv.2008.02.004, 2008.

Boersma, K. F., Jacob, D. J., Trainic, M., Rudich, Y., DeSmedt, I., Dirksen, R., and Eskes, H. J.: Validation of urban $\mathrm{NO}_{2}$ concentrations and their diurnal and seasonal variations observed from the SCIAMACHY and OMI sensors using in situ surface measurements in Israeli cities, Atmos. Chem. Phys., 9, 3867-3879, doi:10.5194/acp-9-3867-2009, 2009.

Boersma, K. F., Eskes, H. J., Dirksen, R. J., van der A, R. J., Veefkind, J. P., Stammes, P., Huijnen, V., Kleipool, Q. L., Sneep, M., Claas, J., Leitão, J., Richter, A., Zhou, Y., and Brunner, D.: An improved tropospheric $\mathrm{NO}_{2}$ column retrieval algorithm for the Ozone Monitoring Instrument, Atmos. Meas. Tech., 4, 19051928, doi:10.5194/amt-4-1905-2011, 2011.
Bruns, M., Buehler, S. A., Burrows, J. P., Richter, A., Rozanov, A., Wang, P., Heue, K. P., Platt, U., Pundt, I., and Wagner, T.: $\mathrm{NO}_{2}$ Profile retrieval using airborne multi axis UV-visible skylight absorption measurements over central Europe, Atmos. Chem. Phys., 6, 3049-3058, doi:10.5194/acp-6-3049-2006, 2006.

Bucsela, E. J., Perring, A. E., Cohen, R. C., Boersma, K. F., Celarier, E. A., Gleason, J. F., Wenig, M. O., Bertram, T. H., Wooldridge, P. J., Dirksen, R., and Veefkind, J. P.: Comparison of tropospheric $\mathrm{NO}_{2}$ from in situ aircraft measurements with near-real-time and standard product data from OMI, J. Geophys. Res., 113, D16S31, doi:10.1029/2007JD008838, 2008.

Burrows, J. P., Richter, A., Dehn, A., Deters, B., Himmelmann, S., Voigt, S., and Orphal, J.: Atmospheric remote-sensing reference data from GOME-2. Temperature-dependent absorption cross sections of $\mathrm{O}_{3}$ in the 231-794 nm range, J. Quant. Spectrosc. Ra., 61, 509-517, 1999.

Chance, K. V. and Spurr, R. J. D.: Ring effect studies: Rayleigh scattering, including molecular parameters for rotational Raman scattering, and the Fraunhofer spectrum, Appl. Optics, 36, 52245230, doi:10.1364/AO.36.005224, 1997.

Chazette, P., Sanak, J., and Dulac, F.: New Approach for Aerosol Profiling with a Lidar Onboard an Ultralight Aircraft: Application to the African Monsoon Multidisciplinary Analysis, Environ. Sci. Technol., 41, 8335-8341, doi:10.1021/es070343y, 2007.

De Maegd, M.: Earth challenge : Sydney-Bruxelles en ULM, La Renaissance du Livre, 2010.

Dieudonné, E.: Analyse multi-instrumentale de l'influence de la variabilité de la hauteur de couche limite sur la distribution verticale des oxydes d'azote en région parisienne, Ph.D. thesis, Université Paris VI-Pierre et Marie Curie, 2012.

Fayt, C., De Smedt, I., Letocart, V., Merlaud, A., Pinardi, G., and Van Roozendael, M.: QDOAS, Software User Manual, Belgian Insitute for Space Aeronomy, Brussels, Belgium, 2011.

Grainger, J. F. and Ring, J.: Anomalous Fraunhofer Line Profiles, Nature, 193, 762, doi:10.1038/193762a0, 1962.

Guibert, S., Matthias, V., Schulz, M., Bosenberg, J., Eixmann, R., Mattis, I., Pappalardo, G., Ritaperrone, M., Spinelli, N., and Vaughan, G.: The vertical distribution of aerosol over Europe synthesis of one year of EARLINET aerosol lidar measurements and aerosol transport modeling with LMDzT-INCA, Atmos. Environ., 39, 2933-2943, doi:10.1016/j.atmosenv.2004.12.046, 2005.

Harder, J. W. and Brault, J. W.: Atmospheric measurements of water vapor in the 442-nm region, J. Geophys. Res., 102, 6245-6252, doi:10.1029/96JD01730, 1997.

Heland, J., Schlager, H., Richter, A., and Burrows, J. P.: First comparison of tropospheric $\mathrm{NO}_{2}$ column densities retrieved from GOME measurements and in situ aircraft profile measurements, Geophys. Res. Lett., 29, 1983, doi:10.1029/2002GL015528, 2002.

Herman, J., Cede, A., Spinei, E., Mount, G., Tzortziou, M., and Abuhassan, N.: $\mathrm{NO}_{2}$ column amounts from ground-based Pandora and MFDOAS spectrometers using the direct-sun DOAS technique: Intercomparisons and application to OMI validation, J. Geophys. Res., 114, D13307, doi:10.1029/2009JD011848, 2009.

Heue, K.-P., Richter, A., Bruns, M., Burrows, J. P., v. Friedeburg, C., Platt, U., Pundt, I., Wang, P., and Wagner, T.: Validation of SCIA- 
MACHY tropospheric $\mathrm{NO}_{2}$-columns with AMAXDOAS measurements, Atmos. Chem. Phys., 5, 1039-1051, doi:10.5194/acp5-1039-2005, 2005.

Jacob, D.: Introduction to Atmospheric Chemistry, Princeton University Press, illustrated Edn., 1999.

Johansson, M., Rivera, C., de Foy, B., Lei, W., Song, J., Zhang, Y., Galle, B., and Molina, L.: Mobile mini-DOAS measurement of the outflow of $\mathrm{NO}_{2}$ and $\mathrm{HCHO}$ from Mexico City, Atmos. Chem. Phys., 9, 5647-5653, doi:10.5194/acp-9-5647-2009, 2009.

Junkermann, W.: An Ultralight Aircraft as Platform for Research in the Lower Troposphere: System Performance and First Results from Radiation Transfer Studies in Stratiform Aerosol Layers and Broken Cloud Conditions, J. Atmos. Ocean. Tech., 18, 934, doi:10.1175/1520-0426(2001)018;0934:AUAAPF $; 2.0 . C O ; 2$, 2001.

Junkermann, W.: On the distribution of formaldehyde in the western Po-Valley, Italy, during FORMAT 2002/2003, Atmos. Chem. Phys., 9, 9187-9196, doi:10.5194/acp-9-9187-2009, 2009.

Kittaka, C., Winker, D. M., Vaughan, M. A., Omar, A., and Remer, L. A.: Intercomparison of column aerosol optical depths from CALIPSO and MODIS-Aqua, Atmos. Meas. Tech., 4, 131-141, doi:10.5194/amt-4-131-2011, 2011.

Kleipool, Q. L., Dobber, M. R., de Haan, J. F., and Levelt, P. F.: Earth surface reflectance climatology from 3 years of OMI data, J. Geophys. Res., 113, D18308, doi:10.1029/2008JD010290, 2008.

Koschmieder, H.: Theorie der horizontalen Sichtweite, Beitrag. Atm. Physik., 12, 33-55, 1926.

Kramer, L. J., Leigh, R. J., Remedios, J. J., and Monks, P. S.: Comparison of OMI and ground-based in situ and MAX-DOAS measurements of tropospheric nitrogen dioxide in an urban area, J. Geophys. Res., 113, D16S39, doi:10.1029/2007JD009168, 2008.

Landulfo, E., Papayannis, A., Artaxo, P., Castanho, A. D. A., de Freitas, A. Z., Souza, R. F., Vieira Junior, N. D., Jorge, M. P. M. P., Sánchez-Ccoyllo, O. R., and Moreira, D. S.: Synergetic measurements of aerosols over São Paulo, Brazil using LIDAR, sunphotometer and satellite data during the dry season, Atmos. Chem. Phys., 3, 1523-1539, doi:10.5194/acp-3-1523-2003, 2003.

Levelt, P., van den Oord, G., Dobber, M., Malkki, A., Visser, H., de Vries, J., Stammes, P., Lundell, J., and Saari, H.: The ozone monitoring instrument, IEEE T. Geosci. Remote., 44, 10931101, doi:10.1109/TGRS.2006.872333, 2006.

Mayer, B. and Kylling, A.: Technical note: The libRadtran software package for radiative transfer calculations - description and examples of use, Atmos. Chem. Phys., 5, 1855-1877, doi:10.5194/acp-5-1855-2005, 2005.

Merlaud, A., Van Roozendael, M., Theys, N., Fayt, C., Hermans, C., Quennehen, B., Schwarzenboeck, A., Ancellet, G., Pommier, M., Pelon, J., Burkhart, J., Stohl, A., and De Mazière, M.: Airborne DOAS measurements in Arctic: vertical distributions of aerosol extinction coefficient and $\mathrm{NO}_{2}$ concentration, Atmos. Chem. Phys., 11, 9219-9236, doi:10.5194/acp-11-9219-2011, 2011.

Munro, R., Eisenger, M., Anderson, C., Callies, J., Carpaccioli, E., Lang, R., Lefevre, A., Livschitz, Y., and Albinana, A.: GOME-2 on MetOp, in: The 2006 EUMETSAT Meteorological Satellite Conference, 2006.
Nebuloni, R.: Empirical relationships between extinction coefficient and visibility in fog, Appl. Optics, 44, 3795-3804, doi:10.1364/AO.44.003795, 2005.

NOAA-NESDIS: Algorithm Theoretical Basis Document For Visibility, Tech. rep., Center for satellite applications and research, 2010.

Palm, S. P., Benedetti, A., and Spinhirne, J.: Validation of ECMWF global forecast model parameters using GLAS atmospheric channel measurements, Geophys. Res. Lett., 32, L22S09, doi:10.1029/2005GL023535, 2005.

Pinardi, G., Lambert, J., Granville, J., Roozendael, M. V., Delcloo, A., Backer, H. D., Valks, P., and Hao, N.: Overview of the validation of GOME-2 total and tropospheric $\mathrm{NO}_{2}$ columns, in: EUMETSAT meteorological satellite conference, 2010.

Platt, U. and Stutz, J.: Differential Optical Absorption Spectroscopy: Principles and Applications, Physics of Earth and Space Environments, Springer, Berlin, 2008.

Prados-Roman, C., Butz, A., Deutschmann, T., Dorf, M., Kritten, L., Minikin, A., Platt, U., Schlager, H., Sihler, H., Theys, N., Van Roozendael, M., Wagner, T., and Pfeilsticker, K.: Airborne DOAS limb measurements of tropospheric trace gas profiles: case studies on the profile retrieval of $\mathrm{O}_{4}$ and $\mathrm{BrO}$, Atmos. Meas. Tech., 4, 1241-1260, doi:10.5194/amt-4-1241-2011, 2011.

Raut, J.-C. and Chazette, P.: Radiative budget in the presence of multi-layered aerosol structures in the framework of AMMA SOP-0, Atmos. Chem. Phys., 8, 6839-6864, doi:10.5194/acp-86839-2008, 2008.

Richter, A., Begoin, M., Hilboll, A., and Burrows, J. P.: An improved NO2 retrieval for the GOME-2 satellite instrument, Atmos. Meas. Tech., 4, 1147-1159, doi:10.5194/amt-4-1147-2011, 2011.

Sabbah, I. and Hasan, F. M.: Remote sensing of aerosols over the Solar Village, Saudi Arabia, Atmos. Res., 90, 170-179, doi:10.1016/j.atmosres.2008.02.004, 2008.

Shaiganfar, R., Beirle, S., Sharma, M., Chauhan, A., Singh, R. P., and Wagner, T.: Estimation of $\mathrm{NO}_{\mathrm{x}}$ emissions from Delhi using Car MAX-DOAS observations and comparison with OMI satellite data, Atmos. Chem. Phys., 11, 10871-10887, doi:10.5194/acp-11-10871-2011, 2011.

Vandaele, A.: Measurements of the $\mathrm{NO}_{2}$ absorption crosssection from $42000 \mathrm{~cm}^{-1}$ to $10000 \mathrm{~cm}^{-1}(238-1000 \mathrm{~nm})$ at $220 \mathrm{~K}$ and $294 \mathrm{~K}$, J. Quant. Spectrosc. Ra., 59, 171-184, doi:10.1016/S0022-4073(97)00168-4, 1998.

Volten, H., Brinksma, E. J., Berkhout, A. J. C., Hains, J., Apituley, J. B., Bergwerff, Van der Hoff, G. R. A., Dirksen, R. J., CalabrettaJongen, S., and Swart, D. P. J.: $\mathrm{NO}_{2}$ lidar profile measurements for satellite interpretation and validation, J. Geophys. Res., 114, D24301, doi:10.1029/2009JD012441, 2009.

WHO: Health aspects of air pollution with particulate matter, ozone, and nitrogen dioxide, Report on a WHO working group, World Health Organization, 2003. 